\title{
Comparison of lifestyle, hormonal and medical factors in women with sporadic and Lynch syndrome-associated endometrial cancer: A retrospective case-case study
}

\author{
MARI H. AALTONEN ${ }^{1 *}$, SYNNÖVE STAFF $^{1,2^{*}}$, JUKKA-PEKKA MECKLIN $^{3}$, \\ KIRSI PYLVÄNÄINEN ${ }^{4}$ and JOHANNA U. MÄENPÄÄ $\ddot{A}^{1,3}$ \\ ${ }^{1}$ Department of Obstetrics and Gynecology, Tampere University Hospital, 33521 Tampere; ${ }^{2}$ Laboratory of \\ Cancer Biology, BioMediTech, University of Tampere, 33520 Tampere; Departments of ${ }^{3}$ Surgery, and \\ ${ }^{4}$ Education and Research, Jyväskylä Central Hospital and University of Eastern, 40620 Jyväskylä; \\ ${ }^{5}$ School of Medicine, University of Tampere, 33014 Tampere, Finland
}

Received October 26, 2016; Accepted February 8, 2017

DOI: $10.3892 / \mathrm{mco} .2017 .1211$

\begin{abstract}
Data available on lifestyle-associated hormonal and medical factors among endometrial cancer (EC)-affected women who carry the Lynch syndrome (LS) mutation is limited. The aim of the present retrospective case study was to compare the reproductive and medical history, as well as lifestyle-associated factors, among patients with LS and sporadic EC. The study population consisted of 50 verified germline mismatch repair (MMR) gene mutation carriers diagnosed with EC, and 110 sporadic EC patients. Data were collected using postal questionnaires. Apart from the mean age at the time of the EC diagnosis (LS, 48.7 years compared with sporadic patients, 55.2 years; $\mathrm{P}<0.0001)$, the characteristics of sporadic and LS EC patients were similar with regard to body mass index (BMI) at age 18, 40 or at the time of the survey, and smoking and alcohol consumption. LS women reported a significantly lower rate of spontaneous abortion $(\mathrm{P}=0.043)$ and also more frequent use of contraceptives $(\mathrm{P}=0.004)$. The prevalence of co-morbidities, including diabetes, atherosclerosis, hypercholesterolemia and hypertension, was similar between the LS and the sporadic groups. A trend for a higher prevalence of endometriosis among mutation carriers was detected (16.0 vs. $8.1 \%, \mathrm{P}=0.137)$. As anticipated, the prevalence of gastrointestinal tract, urinary tract and ovarian cancer was higher among the LS women $(\mathrm{P}<0.0001, \mathrm{P}=0.006$ and $\mathrm{P}=0.056$, respectively). Co-morbidity and lifestyle-associated
\end{abstract}

Correspondence to: Dr Mari H. Aaltonen, Department of Obstetrics and Gynecology, Tampere University Hospital, P.O. Box 2000, 33521 Tampere, Finland

E-mail: mari.aaltonen@pshp.fi

*Contributed equally

Key words: Lynch syndrome, endometrial cancer, lifestyle factors factors appeared to be comparable among patients with LS and sporadic EC. The reported difference in the use of contraceptives warrants further investigation. Future studies are also required to address the possible association between LS and endometriosis.

\section{Introduction}

Lynch syndrome (LS), also called hereditary non-polyposis colorectal cancer (HNPCC), is a dominantly inherited cancer predisposition syndrome caused by germline mutations in the DNA mismatch repair (MMR) genes, MLH1, MSH2, MSH6, and PMS2. In addition to the early occurrence of colorectal cancer (CRC), LS is also characterized by certain extracolonic cancers (ECCs), of which EC is the most common (1). The lifetime risk of EC varies between 32 and $60 \%$, according to previous studies (2-4). Inactivation of the LS genes leads to loss of MMR proteins and results in microsatellite instability (MSI), which is typical for LS-associated EC. MSI is present in $64 \%$ of LS-associated EC tumors, and only in $15 \%$ of sporadic EC tumors (5-7).

The common risk factors for EC in the general population, i.e. in non-carriers of MMR mutations, have been well-characterized in several studies: The EC risk rises by nulliparity, obesity, hypertension, high blood glucose levels, ovulation failure, non-use of hormonal contraceptives, estrogen use, estrogen-producing tumors and use of tamoxifen $(8,9)$. Few studies have correlated MMR expression with body mass index (BMI), lifestyle habits and medical history in unselected EC, suggesting an association between lower BMI and a loss of MMR expression (10-12). However, data are limited on lifestyle, hormonal and medical factors in mutation-verified LS-associated EC. Previous studies reporting BMI in EC-affected LS women have elicited contradictory results (13-16).

The aim of the present study was to characterize lifestyle factors and the medical and reproductive history, in EC-affected verified LS mutation carriers and in sporadic EC patients having no familial history of cancer. 


\section{Materials and methods}

Study subjects. The present retrospective case study was performed at Tampere University Hospital (TAUH), Tampere, Finland. The study protocol was approved by the TAUH Ethical Committee. The study population consisted of Finnish female LS mutation carriers diagnosed with EC in eight Central and five University Hospitals across Finland between January 1992 and December 2010 (Table I). All LS patients with EC tested positive for germ-line mutations associated with LS between January 1996 and December 2009, and this Finnish LS registry has been previously characterized (9). The distribution of different germ-line mutations among LS EC patients $(n=50)$ was as follows: MSH2, 8 patients (16\%); MLH1, 39 patients (78\%); and MSH6, 3 patients (6\%).

The control population consisted of Finnish women with sporadic EC treated at Tampere University Hospital between January 2002 and December 2009 showing no familial history of cancer. Questionnaires addressing reproductive and medical history were mailed to $78 \mathrm{LS}$ and 290 sporadic EC patients. Questionnaires were re-sent to patients who did not return questionnaires in 6 months from the first mailing. Finally, data from the returned questionnaires were collected from a total of $50 \mathrm{LS}$ and 110 sporadic EC patients. All participants in the present study provided their informed consent.

Questionnaires. Participants in the study were recruited to complete a questionnaire collecting data on height, present weight and weight at the ages of 18 and 40 years, parity, number of abortions and miscarriages, age at menarche and menopause, history of ovulation failure, polycystic ovaries and endometriosis, use of hormone replacement therapy (HRT) and hormonal contraception, smoking habits, alcohol consumption, history of other types of cancer and chronic illnesses. A detailed description of the questionnaire content is presented in Table II.

Statistical analysis. IBM SPSS statistics software, version 22 (IBM SPSS, Inc., Armonk, NY, USA) was used for the statistical analyses. BMI, alcohol consumption, the cumulative number of smoked cigarettes as pack-years, number of deliveries, number of induced and spontaneous abortions, age at menarche and menopause, and the duration of HRT or contraceptive use were statistically compared among patients with LS and sporadic EC. The comparison of means was performed using Student's $t$-test, and comparison of categorical variables (induced and spontaneous abortions) was performed using a Chi-square test. The prevalence of ever use of HRT or hormonal contraception, ever smoking, endometriosis, ovulation failure, diabetes mellitus (DM), atherosclerosis, hypercholesterolemia, hypertension and hypothyreosis was compared among patients with LS and sporadic EC using a Chi-square test. The prevalence of gastrointestinal tract, urinary tract, breast and ovarian cancer (OC) types was also compared among patients with LS and sporadic EC using a Chi-square test. Two-tailed $\mathrm{P}<0.05$ values were considered to indicate statistically significant differences.
Table I. Hospitals of LS EC patients featured in the present study.

\begin{tabular}{ll}
\hline Name of hospital & \multicolumn{1}{c}{ Location } \\
\hline Tampere University Hospital & Tampere, Finland \\
Helsinki University Hospital & Helsinki, Finland \\
Oulu University Hospital & Oulu, Finland \\
Kuopio University Hospital & Kuopio, Finland \\
Turku University Hospital & Turku, Finland \\
Jyväskylä Central Hospital & Jyväskylä, Finland \\
Päijät-Häme Central Hospital & Lahti, Finland \\
Kanta-Häme Central Hospital & Hämeenlinna, Finland \\
Seinäjoki Central Hospital & Seinäjoki, Finland \\
Rovaniemi Central Hospital & Rovaniemi, Finland \\
Pohjois-Karjala Central Hospital, & Joensuu, Finland \\
Kotka Central Hospital & Kotka, Finland \\
Satakunta Central Hospital & Pori, Finland
\end{tabular}

LS, Lynch syndrome; EC, endometrial carcinoma.

\section{Results}

Questionnaire response rates were 67 and $38 \%$ among patients with LS and sporadic EC, respectively. The mean age of the patients at the time of EC diagnosis was 49.2 (range, 36-66) and 55.6 (range, 42-72) years among patients with LS and sporadic EC, respectively $(\mathrm{P}<0.0001)$. Patients with $\mathrm{LS}$ and sporadic $\mathrm{EC}$ at the time of the survey were also significantly younger compared with their sporadic EC counterparts (mean age, 65.0 vs. 72.4 years; $\mathrm{P}=0.0001$ ). The mean $\mathrm{BMI}$ values reported in the survey at the ages of 18 or 40 years were similar, as was the proportion of overweight patients (reporting a BMI >25) among mutation carriers in comparison with sporadic EC patients.

Self-reported lifestyle habits, including smoking and alcohol consumption, did not differ among patients with LS and sporadic EC.

Reproductive factors appeared to be similar among the study and control patients, with the exception of the number of spontaneous abortions and the use of hormonal contraception. Only $10 \%$ of the patients with LS and sporadic EC reported one or more spontaneous abortions compared with $24 \%$ of sporadic EC patients $(\mathrm{P}=0.043)$, and the ever use of hormonal contraception was more frequent among mutation carriers compared with sporadic EC women (56.0 vs. 32.7\%; $\mathrm{P}=0.004$ ).

LS women seemed to use HRT more frequently in the survey responses compared with sporadic EC patients (16.0 vs. $6.3 \% ; \mathrm{P}=0.05)$, although in the logistic regression analysis, only a younger age in the survey among LS women remained as a significant co-variant.

A total of $16 \%$ of the patients with LS and sporadic EC, and $8.1 \%$ of the sporadic EC patients had been diagnosed with endometriosis $(\mathrm{P}=0.137)$. Self-reported prevalence of chronic illnesses, including hypertension, atherosclerosis, DM, hypothyreosis and hypercholesterolemia, was similar among patients with LS and sporadic EC. The prevalence of 
Table II. Details of the questionnaire sent on to patients with LS and sporadic EC.

\begin{tabular}{|c|c|c|}
\hline Feature & Further information & Measurement/response \\
\hline Height & & $\mathrm{cm}$ \\
\hline \multirow[t]{3}{*}{ Weight } & At an age of 18 & $\mathrm{~kg}$ \\
\hline & At an age of 40 & $\mathrm{~kg}$ \\
\hline & At present & $\mathrm{kg}$ \\
\hline Age at menarche & & Years \\
\hline Age at menopause if achieved & & Years \\
\hline \multirow[t]{4}{*}{ Number of pregnancies } & & Number \\
\hline & Deliveries & Number \\
\hline & Miscarriages & Number \\
\hline & Induced abortions & Number \\
\hline Vaginal HRT use? & & $\mathrm{Y} / \mathrm{N}$ \\
\hline Systemic HRT use? & & $\mathrm{Y} / \mathrm{N}$ \\
\hline \multirow[t]{2}{*}{ If yes: } & Systemic HRT duration & Years \\
\hline & Systemic HRT at present & $\mathrm{Y} / \mathrm{N}$ \\
\hline Ovulation failure & & $\mathrm{Y} / \mathrm{N}$ \\
\hline $\mathrm{PCO}$ & & $\mathrm{Y} / \mathrm{N}$ \\
\hline Endometriosis & & $\mathrm{Y} / \mathrm{N}$ \\
\hline \multirow[t]{4}{*}{ If yes, any treatment? } & & $\mathrm{Y} / \mathrm{N}$ \\
\hline & Contraceptive tablets & $\mathrm{Y} / \mathrm{N}$ \\
\hline & Progesterone po & $\mathrm{Y} / \mathrm{N}$ \\
\hline & Progesterone-IUD & $\mathrm{Y} / \mathrm{N}$ \\
\hline Cancer other than EC? & & $\mathrm{Y} / \mathrm{N}$ \\
\hline \multirow[t]{4}{*}{ If yes: } & GI tract cancer & $\mathrm{Y} / \mathrm{N}$ \\
\hline & Urinary tract cancer & $\mathrm{Y} / \mathrm{N}$ \\
\hline & Breast cancer & $\mathrm{Y} / \mathrm{N}$ \\
\hline & Ovarian cancer & $\mathrm{Y} / \mathrm{N}$ \\
\hline Operated for cancer? & & $\mathrm{Y} / \mathrm{N}$ \\
\hline LS gynecological follow-up duration & & Years \\
\hline Regular smoker? & & $\mathrm{Y} / \mathrm{N}$ \\
\hline \multirow[t]{2}{*}{ If yes: } & Cigarettes per day & Number \\
\hline & Duration of smoking & Years \\
\hline Alcohol consumption? & & $\mathrm{Y} / \mathrm{N}$ \\
\hline \multirow[t]{2}{*}{ If yes: } & Servings/week & Number \\
\hline & Duration of consumption & Years \\
\hline \multirow[t]{2}{*}{ Diabetes? } & Insulin treatment & $\mathrm{Y} / \mathrm{N}$ \\
\hline & Tablet treatment & $\mathrm{Y} / \mathrm{N}$ \\
\hline Hypertension? & & $\mathrm{Y} / \mathrm{N}$ \\
\hline MCC? & & $\mathrm{Y} / \mathrm{N}$ \\
\hline Hypothyreosis? & & $\mathrm{Y} / \mathrm{N}$ \\
\hline Hypercholesterolemia? & & $\mathrm{Y} / \mathrm{N}$ \\
\hline Atherosclerosis? & & $\mathrm{Y} / \mathrm{N}$ \\
\hline Any other serious condition? If so, which? & & List \\
\hline Hormonal contraception? & & $\mathrm{Y} / \mathrm{N}$ \\
\hline If yes: & Duration of use & Years \\
\hline Medication & & List \\
\hline
\end{tabular}

LS, Lynch syndrome; EC, endometrial carcinoma; HRT, hormone replacement therapy; PO, peroral; PCO, polycystic ovaries; IUD, intrauterine device; MCC, coronary heart disease; GI, gastrointestinal.

gastrointestinal tract cancer (48 vs. $0 \%$; $\mathrm{P}<0.0001)$, urinary tract cancer $(12$ vs. $2 \% ; \mathrm{P}=0.006)$ and $\mathrm{OC}(6$ vs. $0.01 \%$;
$\mathrm{P}=0.056$ ) was higher among LS patients in comparison with sporadic EC patients. 
Table III. BMI and lifestyle habits among LS women with EC compared with patients with sporadic EC.

\begin{tabular}{|c|c|c|c|c|}
\hline Parameter & Total EC, $(n=160)$ & LS-associated EC $(n=50)$ & Sporadic EC (n=110) & P-value \\
\hline \multicolumn{5}{|l|}{ BMI, mean (SD) } \\
\hline At age of 18 & $21.6(2.7)$ & $21.4(2.1)$ & $21.7(3.0)$ & $0.525^{\mathrm{a}}$ \\
\hline At age of 40 & $24.4(4.0)$ & $24.5(4.5)$ & $24.3(3.7)$ & $0.828^{\mathrm{a}}$ \\
\hline At survey & $27.4(5.4)$ & $27.2(5.3)$ & $27.5(5.4)$ & $0.697^{\mathrm{a}}$ \\
\hline \multicolumn{5}{|l|}{$\mathrm{BMI}>25, \mathrm{n}(\%)$} \\
\hline At age of 18 & $18(11.3)$ & $3(6.0)$ & $15(14.0)$ & $0.157^{\mathrm{b}}$ \\
\hline At age of 40 & $68(42.5)$ & $28(56.0)$ & $40(36.0)$ & $0.334^{\mathrm{b}}$ \\
\hline At the time of the survey & $104(65.0)$ & $31(62.0)$ & $73(66.0)$ & $0.592^{\mathrm{b}}$ \\
\hline \multicolumn{5}{|l|}{ Tobacco use, n (\%) } \\
\hline Yes & $37(23.0)$ & $15(30.0)$ & $22(20.0)$ & $0.164^{\mathrm{a}}$ \\
\hline No & $123(77.0)$ & $35(70.0)$ & $88(80.0)$ & \\
\hline Smoking, pack years ${ }^{c}$ & 7.55 & 5.53 & 9.95 & $0.137^{\mathrm{b}}$ \\
\hline Alcohol consumption $^{\mathrm{d}}$ & 1.9 & 1.7 & 2.1 & $0.354^{\mathrm{a}}$ \\
\hline
\end{tabular}

${ }^{\mathrm{a}}$ According to Student's $t$-test. ${ }^{\mathrm{b}}$ According to Pearson's Chi-square test. ${ }^{\mathrm{c}} \mathrm{A}$ 'pack year' is defined as 20 cigarettes a day for 1 year. ${ }^{\mathrm{d}} \mathrm{Mean}$ number of servings of alcohol per week. BMI, body mass index; EC, endometrial cancer; LS, Lynch syndrome; SD, standard deviation.

Table IV. Prevalence of factors associated with reproduction among LS women with EC compared with patients with sporadic EC.

\begin{tabular}{|c|c|c|c|c|}
\hline Factor & Total EC $(n=160)$ & LS-associated EC $(\mathrm{n}=50)$ & Sporadic EC $(n=110)$ & P-value \\
\hline No. of pregnancies ${ }^{a}$ & 2.15 & 2.25 & 2.04 & $0.431^{\mathrm{b}}$ \\
\hline No. of deliveries ${ }^{a}$ & 1.79 & 1.84 & 1.73 & $0.594^{\mathrm{b}}$ \\
\hline \multicolumn{5}{|l|}{ Spontaneous abortions, n (\%) } \\
\hline 0 & $129(80.6)$ & $45(90.0)$ & $84(76.4)$ & $0.043^{\mathrm{c}}$ \\
\hline$\geq 1$ & $31(19.4)$ & $5(10.0)$ & $26(23.6)$ & \\
\hline \multicolumn{5}{|l|}{ Induced abortions, n (\%) } \\
\hline 0 & $140(87.5)$ & $47(94.0)$ & $93(84.5)$ & $0.094^{\mathrm{c}}$ \\
\hline$\geq 1$ & $20(12.5)$ & $3(6.0)$ & $17(15.5)$ & \\
\hline Age at menarche ${ }^{a}$ & 13.6 & 13.4 & 13.7 & $0.375^{\mathrm{b}}$ \\
\hline Age at menopause ${ }^{a}$ & 50.4 & $50.3^{\mathrm{d}}$ & $50.5^{\mathrm{e}}$ & $0.878^{\mathrm{b}}$ \\
\hline Duration of HRT use, years ${ }^{\mathrm{a}, \mathrm{f}}$ & - & 11.3 & 9.7 & $0.407^{\mathrm{b}}$ \\
\hline $\begin{array}{l}\text { Duration of hormonal contraception } \\
\text { use, years }^{\mathrm{a}}\end{array}$ & - & 6.6 & 6.9 & 0.83 \\
\hline
\end{tabular}

${ }^{\mathrm{a}}$ The mean values are indicated. ${ }^{\mathrm{b}}$ According to the Student's $t$-test. ${ }^{\mathrm{c}}$ According to the Pearson Chi-square test. ${ }^{\mathrm{d}} \mathrm{n}=21 ;{ }^{\mathrm{e}} \mathrm{n}=69$. ${ }^{\mathrm{f}}$ Regarding ever users of HRT, $n=25$ LS patients and $n=61$ sporadic EC patients. EC, endometrial cancer; LS, Lynch syndrome; HRT, hormone replacement therapy.

Comparisons of BMI, lifestyle habits, reproductive history, prevalence of chronic illnesses, hormonal therapy use and history of cancer among the patients with LS and sporadic EC are summarized in Tables III-VI.

\section{Discussion}

In the present case study, data on self-reported reproductive and medical histories in verified LS mutation carriers in comparison with sporadic EC patients are reported. According to these results, co-morbidity and prevalence of lifestyle-associated factors appeared to be comparable among patients with
LS and sporadic EC. However, ever use of hormonal contraceptives was more common among mutation carriers, who also reported having fewer spontaneous and induced abortions compared with their sporadic counterparts. Furthermore, a trend of higher prevalence of endometriosis among mutation carriers was detected. As expected, GI-tract, urogenital tract and ovarian malignancies were more frequent among LS mutation carriers.

Previously published studies describing BMI or environmental factors in suspected LS populations have presented contradictory results. These studies have suggested that EC women with a family history of CRC or suspected LS appear 
Table V. Self-reported prevalence of chronic medical conditions and use of hormonal therapy among LS women with EC compared with patients with sporadic EC.

\begin{tabular}{|c|c|c|c|c|}
\hline Therapy or condition, $\mathrm{n}(\%)$ & Total EC $(n=160)$ & LS-associated EC ( $\mathrm{n}=50)$ & Sporadic EC $(n=110)$ & P-value \\
\hline \multicolumn{5}{|l|}{ Ever use of HRT } \\
\hline Yes & $86(54)$ & $25(50)$ & $61(55)$ & \multirow[t]{2}{*}{0.521} \\
\hline No & $74(46)$ & $25(50)$ & $49(45)$ & \\
\hline \multicolumn{5}{|l|}{ HRT use at present } \\
\hline Yes, & $15(9)$ & $8(16)$ & $7(6)$ & \multirow[t]{2}{*}{$0.05^{\mathrm{b}}$} \\
\hline No & $145(91)$ & $42(84)$ & $103(94)$ & \\
\hline \multicolumn{5}{|c|}{ Ever-use of hormonal contraception } \\
\hline Yes & $65(41)$ & $29(58)$ & $36(33)$ & \multirow[t]{2}{*}{0.004} \\
\hline No & $95(59)$ & $21(42)$ & $74(67)$ & \\
\hline \multicolumn{5}{|l|}{ Ovulation failure } \\
\hline Yes & $16(10)$ & $4(8)$ & $12(11)$ & \multirow[t]{2}{*}{0.570} \\
\hline No & $144(90)$ & $46(92)$ & $98(89)$ & \\
\hline \multicolumn{5}{|l|}{ Endometriosis } \\
\hline Yes & $17(11)$ & $8(16)$ & $9(8)$ & \multirow[t]{2}{*}{0.137} \\
\hline No & $143(89)$ & $42(84)$ & $101(92)$ & \\
\hline \multicolumn{5}{|l|}{ Diabetes mellitus } \\
\hline Yes & $23(14)$ & $6(12)$ & $17(15)$ & \multirow[t]{2}{*}{0.665} \\
\hline No & $137(86)$ & $44(88)$ & $93(85)$ & \\
\hline \multicolumn{5}{|l|}{ Atherosclerosis } \\
\hline Yes & $10(6)$ & $1(2)$ & $9(8)$ & \multirow[t]{2}{*}{0.134} \\
\hline No & $150(94)$ & $49(98)$ & $101(92)$ & \\
\hline \multicolumn{5}{|l|}{ Hypercholesterolemia } \\
\hline Yes & $51(32)$ & $14(28)$ & $37(34)$ & \multirow[t]{2}{*}{0.478} \\
\hline No & $109(68)$ & $36(72)$ & $73(66)$ & \\
\hline \multicolumn{5}{|l|}{ Hypertension } \\
\hline Yes & $70(44)$ & $18(36)$ & $52(47)$ & \multirow[t]{2}{*}{0.183} \\
\hline No & $90(56)$ & $32(64)$ & $58(53)$ & \\
\hline \multicolumn{5}{|l|}{ Hypothyreosis } \\
\hline Yes & $21(13)$ & $6(12)$ & $15(14)$ & \multirow[t]{2}{*}{0.776} \\
\hline No & $139(87)$ & $44(88)$ & $95(86)$ & \\
\hline
\end{tabular}

${ }^{a}$ According to the Pearson Chi-square test. ${ }^{b}$ In the logistic regression analysis, only the age at the time of the survey remained a statistically significant covariate. EC, endometrial cancer; LS, Lynch syndrome; HRT, hormone replacement therapy.

to be obese less often compared with EC women with no CRC family history (14-18). However, Lynch mutation carriers with EC have also been reported to be more obese compared with women with sporadic EC (16), whereas others (13) have reported no significant difference in BMI between these two patient groups, which is in line with the results presented in the current study. Even though our LS cohort included only 50 EC cases, all of them were verified germline MMR gene mutation carriers, and in comparison with previous descriptive studies, the cohort was relatively large.

Several studies of unselected EC cohorts have revealed a positive association between MSI or MMR protein expression positivity and a higher BMI and older age at the time of EC diagnosis (10-12). However, these previous studies have used indirect measurements of LS (i.e., absent MMR protein expression or MSI) instead of germline mutation testing.
Consistently with previous studies $(14,16)$, no differences in the prevalence of DM or other chronic illnesses between the study groups were identified in the current study. With regard to BMI and other co-morbidities, the similarities between LS and sporadic EC patient cohorts may imply that sporadic and hereditary EC patients share a common risk factor profile. However, such conclusions cannot be drawn from the type of data presented in the current study.

To date, only two comprehensive retrospective cohort studies of verified LS populations have been published with regard to EC risk $(19,20)$. According to these studies, risk factors are partially shared in sporadic and hereditary EC, since the BMI appeared not to have an effect on EC risk, although parity, longer use of hormonal contraceptives and a later age at menarche reduced the risk of EC in LS women $(19,20)$. It has been suggested that LS women have more non-endometrioid 
Table VI. Cancer prevalence among women with EC with or without an inherited predisposition.

\begin{tabular}{|c|c|c|c|c|}
\hline Type of cancer, n(\%) & Total EC $(n=160)$ & LS-associated EC $(\mathrm{n}=50)$ & Sporadic EC $(n=110)$ & P-value ${ }^{a}$ \\
\hline \multicolumn{5}{|l|}{ GI-tract cancer } \\
\hline Yes & $24(15)$ & $24(48)$ & $0(0)$ & \multirow[t]{2}{*}{$<0.0001$} \\
\hline No & $136(85)$ & $26(52)$ & $110(100)$ & \\
\hline \multicolumn{5}{|l|}{ Urinary tract cancer } \\
\hline Yes & $8(5)$ & $6(12)$ & $2(2)$ & \multirow[t]{2}{*}{0.006} \\
\hline No & $152(95)$ & $44(88)$ & $108(98)$ & \\
\hline \multicolumn{5}{|l|}{ Breast cancer } \\
\hline Yes & $5(3)$ & $3(6)$ & $2(2)$ & \multirow[t]{2}{*}{0.159} \\
\hline No & $155(97)$ & 47 (94) & $108(98)$ & \\
\hline \multicolumn{5}{|l|}{ Ovarian cancer } \\
\hline Yes & $4(3)$ & $3(6)$ & $1(1)$ & \multirow[t]{2}{*}{0.056} \\
\hline No & $156(97)$ & 47 (94) & 109 (99) & \\
\hline
\end{tabular}

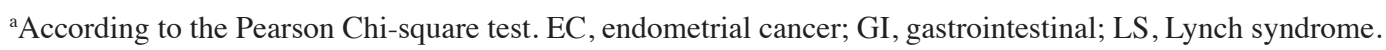

tumors compared with sporadic patients, which could at least partly explain certain of the differences in the reported risk factor profiles (19-21).

LS mutation carriers in the present study used hormonal contraceptives more frequently than non-carriers. This may reflect EC risk-reducing strategies recommended for mutation carriers, or improved standards of advisory family planning. Only a few studies have previously addressed the influence of contraceptive use on ECC risk among LS women $(13,19)$. No significant effect of contraceptive use on the ECC risk was detected among MLH1 mutation carriers in the study of Blokhuis et al (13), although that study included only 12 cases of EC in 87 mutation-positive females, in comparison with 121 mutation-negative female relatives. However, the previously described large retrospective cohort study revealed a marked EC risk reduction among LS mutation carriers with a history of contraceptive use extending to 1 year (19). The results of the present study, demonstrating fewer spontaneous and induced abortions among mutation carriers, may also be interpreted as more premeditated family planning being carried out for the LS mutation carriers tested at a fertile age, and this warrants further investigation.

LS women reported endometriosis two times more frequently than sporadic EC patients. However, the present study was not able to detect statistically significant associations between more frequent diagnosis of endometriosis and LS-associated EC. It is intriguing to speculate that genetic factors conferring EC predisposition may also be partly involved in the pathogenesis of endometriosis. LS women also have an increased risk for $\mathrm{OC}$, as also demonstrated in the present case study and, more specifically, for endometrioid OC and the clear-cell type of OC (2). Endometrioid and clear-cell $\mathrm{OC}$ are speculated to possibly originate from endometriotic foci undergoing a malignant transformation (22). Notably, a small series of LS prophylactic surgery specimens revealed endometriosis in up to $20 \%$ of samples (23). Taken together, this interesting finding of possible association of LS with endometriosis warrants future studies at a larger scale.
There were limitations to our study. First, the study was descriptive and did not provide data on actual environmental EC risk factors for genetically predisposed LS women, but nevertheless produced qualitative data on features of sporadic and hereditary EC cohorts. As anticipated, the response rate was markedly higher among LS mutation carriers, and this may have introduced bias into the analysis. The positive family history and verified mutation status may be associated with a higher participation rate and a more positive attitude towards questionnaire studies. EC patients with LS were younger than sporadic patients at the time of diagnosis and at the time of the survey, which could have had an influence on the distribution of time-dependent factors, and this should be taken into account when interpreting the results. The data were only collected from EC survivors, and self-reported retrospective data were based on patients' memory. This may have led to bias and under-reporting. However, it has been demonstrated that, for example, weight measures based on patients' memory actually correlate well (24).

In conclusion, the present case study has reported on self-reported reproductive and medical histories in verified LS mutation carriers compared with sporadic EC patients. The BMI, co-morbidity and lifestyle-associated factors appeared to be comparable between LS and sporadic EC patient cohorts. Ever use of hormonal contraceptives was more common among mutation carriers, and they appeared to have undergone fewer spontaneous and induced abortions. These findings may reflect more premeditated family planning in LS mutation carriers tested for mutations at a fertile age, providing an interesting target for future research. A trend of higher prevalence of endometriosis among mutation carriers was also detected, similarly warranting further investigation at a larger scale.

\section{Acknowledgements}

This study was funded by the Finnish Cancer Society and Competitive Research Funding of the Tampere University Hospital (grant no. 9S040). 


\section{References}

1. Mecklin JP and Järvinen HJ: Tumor spectrum in cancer family syndrome (hereditary nonpolyposis colorectal cancer). Cancer 68: 1109-1112, 1991.

2. Aarnio M, Sankila R, Pukkala E, Salovaara R, Aaltonen LA, de la Chapelle A, Peltomäki P, Mecklin JP and Järvinen HJ: Cancer risk in mutation carriers of DNA-mismatch-repair genes. Int J Cancer 81: 214-218, 1999.

3. Dunlop MG, Farrington SM, Carothers AD, Wyllie AH, Sharp L, Burn J, Liu B, Kinzler KW and Vogelstein B: Cancer risk associated with germline DNA mismatch repair gene mutations. Hum Mol Genet 6: 105-110, 1997.

4. Quehenberger F, Vasen HF and van Houwelingen HC: Risk of colorectal and endometrial cancer for carriers of mutations of the hMLH1 and hMSH2 gene: Correction for ascertainment. J Med Genet 42: 491-496, 2005.

5. Nieminen TT, Gylling A, Abdel-Rahman WM, Nuorva K, Aarnio M, Renkonen-Sinisalo L, Järvinen HJ, Mecklin JP, Bützow R and Peltomäki P: Molecular analysis of endometrial tumorigenesis: Importance of complex hyperplasia regardless of atypia. Clin Cancer Res 15: 5772-5783, 2009.

6. Vasen HF, Stormorken A, Menko FH, Nagengast FM Kleibeuker JH, Griffioen G, Taal BG, Moller P and Wijnen JT: MSH2 mutation carriers are at higher risk of cancer than MLH1 mutation carriers: A study of hereditary nonpolyposis colorectal cancer families. J Clin Oncol 19: 4074-4080, 2001.

7. Wijnen J, de Leeuw W, Vasen H, van der Klift H, Møller P, Stormorken A, Meijers-Heijboer H, Lindhout D, Menko F, Vossen S, et al: Familial endometrial cancer in female carriers of MSH6 germline mutations. Nat Genet 23: 142-144, 1999.

8. Collaborative Group on Epidemiological Studies on Endometrial Cancer: Endometrial cancer and oral contraceptives: An individual participant meta-analysis of 27276 women with endometrial cancer from 36 epidemiological studies. Lancet Oncol 16: 1061-1070, 2015.

9. Buchanan EM, Weinstein LC and Hillson C: Endometrial cancer. Am Fam Physician 80: 1075-1080, 2009.

10. González L, Ortiz AP, Suárez EL, Umpierre S, Billoch J, Marcos MJ, Joy L, Charneco E, Lacourt MY, Bernabe-Dones RD and Cruz-Correa MR: Case-case study of factors associated to hMLH1, hMSH2 and hMSH6 protein expression among endometrial cancer patients of the university district hospital of san juan, puerto rico. Int J Gynecol Cancer 22: 826-829, 2012.

11. Joehlin-Price AS, Perrino CM, Stephens J, Backes FJ, Goodfellow PJ, Cohn DE and Suarez A A: Mismatch repair protein expression in 1049 endometrial carcinomas, associations with body mass index, and other clinicopathologic variables. Gynecol Oncol 133: 43-47, 2014.

12. Cohn DE, Pavelka JC, Frankel WL, Morrison CD, Hampel H, Copeland LJ and Fowler JM: Correlation between patient weight and defects in DNA mismatch repair: Is this the link between an increased risk of previous cancer in thinner women with endometrial cancer? Int J Gynecol Cancer 18: 136-140, 2008.
13. Blokhuis MM, Pietersen GE, Goldberg PA, Algar U, Van der Merwe L, Mbatani N, Vorster AA and Ramesar RS: Lynch syndrome: The influence of environmental factors on extracolonic cancer risk in hMLH1 c.C1528T mutation carriers and their mutation-negative sisters. Fam Cancer 9: 357-363, 2010.

14. Yoo HJ, Joo J, Seo SS, Kang S, Yoo CW, Park SY and Lim MC: Correlation between body mass index and prevalence of hereditary nonpolyposis colorectal cancer in Korean patients with endometrial cancer. Int J Gynecol Cancer 22: 267-272, 2012.

15. Fornasarig M, Campagnutta E, Talamini R, Franceschi S, Boz G, Scarabelli C, Andreaus CM, Scozzari G and Valentini M: Risk factors for endometrial cancer according to familial susceptibility. Int J Cancer 77: 29-32, 1998

16. Wang Y, Xue F, Broaddus RR, Tao X, Xie SS and Zhu Y: Clinicopathological features in endometrial carcinoma associated with Lynch syndrome in China. Int J Gynecol Cancer 19: 651-656, 2009.

17. Lu KH, Schorge JO, Rodabaugh KJ, Daniels MS, Sun CC, Soliman PT, White KG, Luthra R, Gershenson DM and Broaddus RR: Prospective determination of prevalence of lynch syndrome in young women with endometrial cancer. J Clin Oncol 25: 5158-5164, 2007.

18. Matthews KS, Estes JM, Conner MG, Manne U, Whitworth JM, Huh WK, Alvarez RD, Straughn JM Jr, Barnes MN and Rocconi RP: Lynch syndrome in women less than 50 years of age with endometrial cancer. Obstet Gynecol 111: 1161-1166, 2008.

19. Dashti SG, Chau R, Ouakrim DA, Buchanan DD, Clendenning M, Young JP, Winship IM, Arnold J, Ahnen DJ, Haile RW, et al: Female hormonal factors and the risk of endometrial cancer in lynch syndrome. JAMA 314: 61-71, 2015.

20. Win AK, Dowty JG, Antill YC, English DR, Baron JA, Young JP, Giles GG, Southey MC, Winship I, Lipton L, et al: Body mass index in early adulthood and endometrial cancer risk for mismatch repair gene mutation carriers. Obstet Gynecol 117: 899-905, 2011.

21. Broaddus RR, Lynch HT, Chen LM, Daniels MS, Conrad P, Munsell MF, White KG, Luthra R and Lu KH: Pathologic features of endometrial carcinoma associated with HNPCC: A comparison with sporadic endometrial carcinoma. Cancer 106: 87-94, 2006.

22. Prowse AH, Manek S, Varma R, Liu J, Godwin AK, Maher ER, Tomlinson IP and Kennedy SH: Molecular genetic evidence that endometriosis is a precursor of ovarian cancer. Int J Cancer 119: 556-562, 2006

23. Karamurzin Y, Soslow RA and Garg K: Histologic evaluation of prophylactic hysterectomy and oophorectomy in Lynch syndrome. Am J Surg Pathol 37: 579-585, 2013.

24. Perry GS, Byers TE, Mokdad AH, Serdula MK and Williamson DF: The validity of self-reports of past body weights by U.S. adults. Epidemiology 6: 61-66, 1995. 